\title{
Retirement patterns of couples in Europe
}

\author{
Laura Hospido ${ }^{*}$ and Gema Zamarro²
}

*Correspondence:
laura.hospido@bde.es
${ }^{1}$ Bank of Spain and IZA, Madrid,
Spain
Full list of author information is
available at the end of the article

${ }^{*}$ Correspondence:

(2) nido@bde.es

Full list of author information is

available at the end of the article

\begin{abstract}
In this paper we study the retirement patterns of couples in a multi-country setting using data from the Survey of Health, Aging and Retirement in Europe. In particular we test whether women?s (men?s) transitions out of the labor force are directly related to the actual realization of their husbands? (wives?) transition, using the institutional variation in country-specific early and full statutory retirement ages to instrument the latter. Exploiting the discontinuities in retirement behavior across countries, we find a significant joint retirement effect for women of 21 percentage points. For men, the estimated effect is insignificant. Our empirical strategy allows us to give a causal interpretation to the effect we estimate. In addition, this effect has important implications for policy analysis.
\end{abstract}

JEL Codes: J26, D10, C21

Keywords: Joint retirement; Social security incentives

\section{Introduction}

Continued improvements in life expectancy and fiscal insolvency of public pensions have led to an increase in pension entitlement ages in several countries, especially for women for whom eligibility ages for retirement pensions have been traditionally lower than for men. The success of such policies, however, relies on how responsive individuals are to changes in pension eligibility. In this paper we use longitudinal data from the Survey of Health, Aging and Retirement in Europe (SHARE) to study the determinants of retirement decisions among European couples and how responsive each member of the couple is to their own eligibility to retirement pensions, as well as their partner囚s eligibility induced retirement choice, after controlling for other factors that may affect their retirement decisions.

Numerous studies have shown the importance of Social Security incentives for retirement decisions. The timing of retirement has been found to be in part determined by the incentives imbedded in the rules determining Social Security benefits, as well as employer-provided pension benefits (see Hurd 1990 and Lumsdaine and Mitchell 1999 for reviews). Likewise, other cross-national research published volumes edited by Gruber and Wise $(1999,2004)$ note that there is a strong negative correlation between labor force participation at older ages and the generosity of early retirement benefits. Finally, Coe and Zamarro (2011) find that official retirement ages in Europe are a strong predictor of retirement for men. However, these studies focused mostly on men and little is known about the determinants of women囚s retirement decisions.

○2014 Hospido and Zamarro; licensee Springer. This is an Open Access article distributed under the terms of the Creative Commons Attribution License (http://creativecommons.org/licenses/by/2.0), which permits unrestricted use, distribution, and reproduction in any medium, provided the original work is properly cited. 
Finally, this paper also contributes to the increasing literature that considers retirement as a decision concerning the couple, rather than the individual (Ruhm 1996; Gustman and Steinmeier 2000, 2004, 2009; Blau and Gilleskie et al. 2006; Coile 2004a, 2004b; Michaud 2003; Michaud and Vermeulen 2004; Casanova 2010; Stancanelli and van Soest 2012a, 2012b; Stancanelli 2012; Honoré and de Paula 2013), by providing empirical evidence of joint retirement behavior. The phenomenon of joint retirement refers to the coincidence in time of spouses $\$ retirement and follows the observation that a significant proportion of spouses retire within less than one year of each other, independently of the age difference between them. The left graph of Figure 1 shows the histogram of the age differences between spouses using couples from the waves 1, 2, and 4 of SHARE. The average gap between the husband冈s age and the wife冈s age is of 2.2 years, being this difference quite stable across SHARE countries (with the only exception of Greece, where the average differential is of 4.4 years). The right graph shows the histogram of the differences between the age the husband stopped working and the age his wife did so. As expected by the joint retirement phenomenon, the peak at zero is large and much bigger than the proportion of couples with no age differences among its members. This hints at the presence of joint retirement behavior among couples in Europe.

In this paper we then focus on the retirement patterns of couples and study the complementarity of spouses $\bigotimes$ retirement patterns in continental Europe. This study complements the one of Banks et al. (2010) for England and the US who, focusing on men, found that British men are from 14 to 20 percentage points more likely to retire when their wife reaches state pension age at 60 than their American counterparts. Considering the numerous differences in the labor markets, health insurance and social plans between the UK and US and many European countries, there is no a priori reason to assume that their findings would still hold in Europe. In addition, in contrast with Banks et al. (2010),
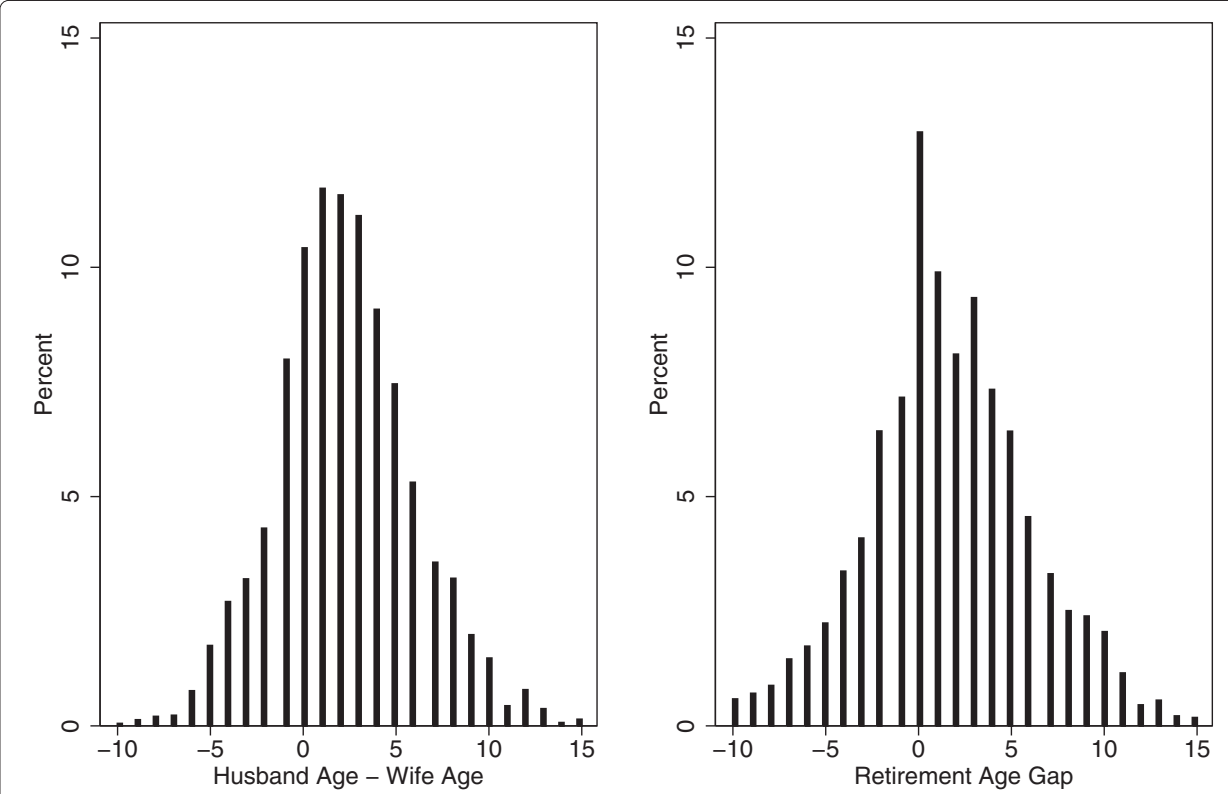

Figure 1 Age gaps between spouses. Notes: Source: SHARE (waves 1, 2, and 4). Retirement age gap = weighted mean of differences between the age of stop working for the husband and the age of stop working for his wife. 
we are interested in studying both women邓s and men邓s transitions out of the labor force and how they directly relate to the actual realization of their husbands $\bigotimes$ (wives $\bigotimes$ ) transition, using the institutional variation in country-specific early and normal retirement ages to instrument the latter.

We find significant evidence of complementarity on spouses $\square$ transitions out of the labor force. The probability of women leaving the labor force increases in around 21 percentage points when their husbands also stop working. The effect for men, however, is insignificant. Controlling for spouse凶s working status reduces the impact of own eligibility for retirement pensions on the probability of leaving the labor force. In particular, the effect for women is reduced in about 2 percentage points for full retirement pensions. Therefore, by ignoring joint retirement, governments would be overstating the impact of eligibility rules on retirement decisions. Our empirical strategy allows us to give a causal interpretation to these effects we estimate as we control for the potential endogeneity of spouse凶s retirement decisions.

The rest of the paper proceeds as follows. Section 2 describes the data and key variables for the analysis. Section 3 discusses the empirical reduced form model and identification strategy. In section 4 we present econometric results from estimating our empirical model. Finally we conclude in section 5 .

\section{Data}

This paper uses data from SHARE, a multidisciplinary and cross-national panel database of micro data on health, socioeconomic status and social and family networks of more than 40,000 individuals aged 50 or over. The main purpose of this survey is to provide detailed information about the living conditions of middle-aged and older people for several countries in Europe. There are currently four waves of data available in SHARE corresponding to the years 2004-2005, 2006-2007, 2008-2009, and 2010-2011. However, the third wave of SHARE (2008-2009) was devoted to a retrospective survey about life events of the respondents and did not collect all the information available in other waves. For this reason, this paper focuses on analysis of waves 1 (2004-2005), 2 (2006-2007), and 4 (2010-2011). The first wave of the SHARE dataset contains a balanced representation of the various European regions, ranging from Scandinavia (Denmark and Sweden), Central Europe (Austria, France, Germany, Switzerland, Belgium, and the Netherlands) and Mediterranean countries (Spain, Italy and Greece). Further data have been collected in 2005-06 and 2006-2007 in Israel. The Czech Republic, Poland and Ireland joined SHARE in the wave 2006-2007. However, Ireland only participated in the wave 2006-2007. Portugal also recently joined the SHARE team and participated in the survey during the last wave of data 2010-2011. To maximize the number of waves of data available we decided to focus our analysis on those OECD countries, for which information on retirement ages is available, who participated in the survey for at least two consecutive waves (i.e. Austria, Belgium, Czech Republic, Denmark, France, Germany, Greece, Italy, the Netherlands, Poland, Spain, Sweden, and Switzerland). ${ }^{1}$

SHARE collects information on health variables (self-reported health, health conditions, physical and cognitive functioning, health behavior, use of health care facilities), biomarkers (grip strength, body-mass index, peak flow), psychological variables (psychological health, well-being, life satisfaction), economic variables (current work activity, job characteristics, opportunities to work, retirement age, sources and composition of current 
income, wealth and consumption, housing, education), and social support variables (assistance within families, transfers of income and assets, social networks, volunteer activities), both at the household and at the individual level. This gives the possibility to analyze a wide variety of questions related to population ageing and the quality of life of the elderly.

In addition, following Coe and Zamarro (2011) we supplemented the SHARE dataset with information regarding country and gender specific statutory ages of eligibility for early and full retirement pensions in order to construct instruments based on dummy variables indicating whether the individual is above the full or early retirement ages set in his country. Table 1 reports the statutory Early and Normal retirement ages in place in each country. Early and Normal retirement ages are based on OECD囚s definitions and represent eligibility ages for early and full retirement pensions, respectively (see, OECD 2003, 2005a, 2005b, 2007, 2009, and 2011). ${ }^{2}$ As it can be seen in this table, the official retirement ages in Europe vary by country, and sometimes by gender, by as much as ten years. Note that for multiple countries in our study retirement ages have been increasing in the period of our analysis. This is the case, for example, in France, Germany or Greece, among others. In such cases, we abstract from the fact that these reforms might only affect certain cohorts in our analysis. We believe this could affect the relevance of our instruments but not its validity. However, as we show later in the paper our instruments continue to be relevant and have a significant effect on transitions out of the labor force, despite this simplification in its definition.

\subsection{Sample}

This paper uses data from three waves of SHARE (waves 1, 2 and 4) for thirteen countries (Austria, Belgium, Czech Republic, Denmark, France, Germany, Greece, Italy, the Netherlands, Poland, Spain, Sweden, and Switzerland). In particular, our sample consists of couples - married or living with a partner - who reported being working in either wave 1 or wave 2 , with both members aged between 50 and 70 , and with both members present in at least two consecutive waves. After dropping observations with incomplete records, our sample has 3,058 such couples. ${ }^{3}$

Given that our aim is to measure the causal effect of joint retirement we focus the analysis on working couples in one wave of data (waves 1 or 2) and study their retirement transitions in the subsequent wave (waves 2 or 4). However, it should be stressed that, for some countries, this sample would not be representative of the whole middleage and older population, especially for women. This is so because, as shown in the Appendix, some European countries (notably the Mediterranean countries) have very high proportions of women who never worked (Figure 4 in the Appendix). Moreover, a large proportion of women who ever worked but stopped before age 50 did so at the early stages of their careers (Figure 5 in the Appendix) . Many of those early career stops are, however, not related to retirement decisions and so they are excluded from our analysis.

\subsection{Definition of retirement}

We define retirement as making a transition out of work between two waves of data. That is, we consider a respondent as having retired if she reports working as her current job status in one wave and reports other working status (i.e. retired, unemployed, permanently sick or disabled, or homemaker) in the subsequent wave of data. In our sample, the 
Table 1 Early and normal retirement ages: men (women)

\begin{tabular}{|c|c|c|c|c|c|c|c|c|c|c|}
\hline & \multicolumn{2}{|c|}{2002} & \multicolumn{2}{|c|}{2005} & \multicolumn{2}{|c|}{2007} & \multicolumn{2}{|c|}{2009} & \multicolumn{2}{|c|}{2011} \\
\hline & Early & Normal & Early & Normal & Early & Normal & Early & Normal & Early & Normal \\
\hline Austria & $60(57)$ & $65(60)$ & $65(60)$ & $65(60)$ & $65(65)$ & $65(65)$ & $65(65)$ & $65(65)$ & $62(60)$ & $65(65)$ \\
\hline Belgium & $60(60)$ & $65(65)$ & $60(60)$ & $65(65)$ & $60(60)$ & $65(65)$ & $60(60)$ & $65(65)$ & $60(60)$ & $65(65)$ \\
\hline Czech Republic & - & - & $60(56-60)$ & $63(59-63)$ & $60(56-60)$ & $63(59-63)$ & $60(59-60)$ & $65(62-65)$ & $60(59-60)$ & $65(62-65)$ \\
\hline Denmark & $65(65)$ & $65(65)$ & $65(65)$ & $65(65)$ & $65(65)$ & $65(65)$ & $65(65)$ & $65(65)$ & $67(67)$ & $67(67)$ \\
\hline France & $57(57)$ & $60(60)$ & $60(60)$ & $60(60)$ & $60(60)$ & $60(60)$ & $61(61)$ & $61(61)$ & $56-60(56-60)$ & $65(65)$ \\
\hline Germany & $63(63)$ & $65(65)$ & $63(63)$ & $65(65)$ & $63(63)$ & $65(65)$ & $63(63)$ & $67(67)$ & $63(63)$ & $67(67)$ \\
\hline Greece & $60(55)$ & $65(60)$ & $57(57)$ & $65(65)$ & $55(55)$ & $65(65)$ & $55(55)$ & $65(65)$ & $55(55)$ & $65(65)$ \\
\hline Italy & $57(57)$ & $65(65)$ & $60(60)$ & $65(65)$ & $60(60)$ & $65(60)$ & $60(60)$ & $65(60)$ & $61(60)$ & $65(60)$ \\
\hline Netherlands & $60(60)$ & $65(65)$ & $60(60)$ & $65(65)$ & $60(60)$ & $65(65)$ & $60(60)$ & $65(65)$ & $65(65)$ & $65(65)$ \\
\hline Poland & - & - & $65(60)$ & $65(60)$ & $65(60)$ & $65(60)$ & $65(60)$ & $65(60)$ & $65(60)$ & $65(60)$ \\
\hline Spain & $60(60)$ & $65(65)$ & $60(60)$ & $65(65)$ & $60(60)$ & $65(65)$ & $60(60)$ & $65(65)$ & $61(61)$ & $65(65)$ \\
\hline Sweden & $61(61)$ & $65(65)$ & $61(61)$ & $65(65)$ & $61(61)$ & $65(65)$ & $61(61)$ & $65(65)$ & $61(61)$ & $65(65)$ \\
\hline Switzerland & $63(62)$ & $65(64)$ & $63(62)$ & $65(64)$ & $63(62)$ & $65(64)$ & $63(62)$ & $65(64)$ & $63(62)$ & $65(64)$ \\
\hline
\end{tabular}

Notes: Retirement ages for women in the Czech Republic vary depending on the number of children. In France, early retirement is possible from 56 under certain circumstances related to working conditions. Source (2002): Natali (2004) supplemented with information from OECD (2003), the Bertelsmann Foundation (2010), Sundén (2004), Preesman (2006), and OECD (2005a). Slight differences can be found between these retirement ages and the ones from OECD publications (e.g. OECD, 2005a) due to the differences between the current law at the time of those publications and the law that was in place when individuals were facing retirement decisions. Source (2005), (2007), (2009), and (2011): OECD (2005b), (2007), (2009), and (2011), respectively. 
percentage of males transitioning out of the labor force is 29 per cent, while for women the percentage is 25 . The proportion actually describing themselves as transitioning into retirement is 25 per cent for men, but only 17 per cent for women. ${ }^{4}$

Figure 2 presents percentages of respondents out of the labor force by age intervals and partner『s labor market status. We find that in our sample the fraction of workers that transition out of the labor force is higher, for both men and women and at every age interval, when the partner also makes such transition.

Some other descriptive statistics for our sample of working couples can be found in the Appendix (Table 4 in the Appendix). The average age of men in our sample is 60 and 58 for women. Eleven per cent of men and a 6.5 percent of women are over the normal retirement age, while 33 and 21.5 percent, respectively, are over the early retirement age. Finally, educational attainment and health status are similar among males and females in our sample of couples.

\section{Empirical model}

We aim to determine the effect of having a partner leaving the labor force on the respondent】s probability of retirement. In particular, let $R_{i}$ be a binary indicator that takes value 1 if respondent $i$ leaves the labor force, and let $R_{j(i)}$ be another indicator that takes value 1 if her partner $j(i)$ also makes such transition, conditional on both members being at work in the previous wave. Then, we consider a reduced form bivariate probit model, for transitions out of the labor force, ${ }^{5,6}$ of the following form:

$$
\begin{aligned}
R_{i} & =1\left[\left(\beta R_{j(i)}+\lambda D_{i}^{\text {early }}+\alpha D_{i}^{\text {normal }}+X_{i, j} \theta^{\prime}\right)>u_{i}\right] \\
R_{j(i)} & =1\left[\left(\gamma D_{j(i)}^{\text {early }}+\delta D_{j(i)}^{\text {normal }}+Z_{i, j} \phi^{\prime}\right)>\epsilon_{i}\right]
\end{aligned}
$$

where $i=\{h, w\}$ stands for husbands and wives, respectively, and $\left(u_{i}, \epsilon_{i}\right) \sim N(0, \Sigma)$.
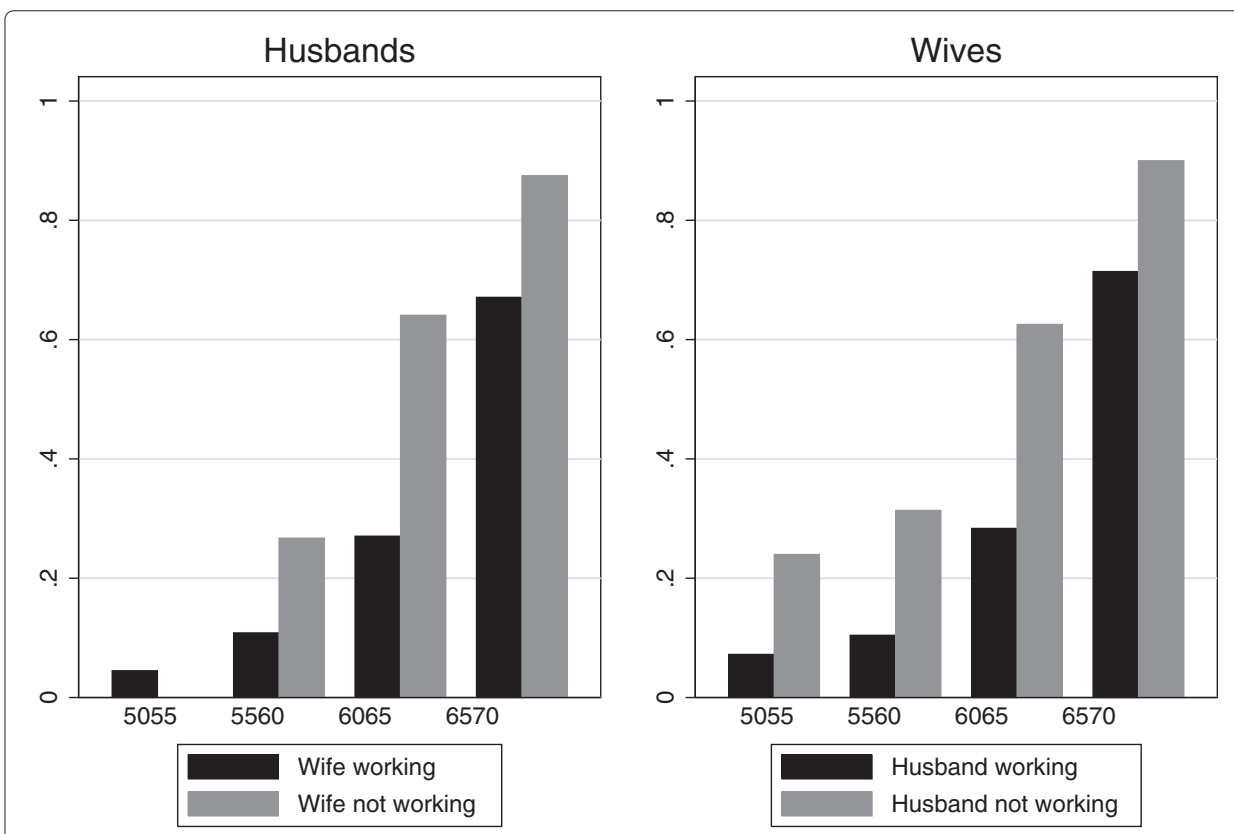

Figure 2 Retirement transitions by age intervals and partner冈s labor market status.Notes: Sample size: Men=3,058; Women=3,058. 
In this framework, $\beta$ is our main parameter of interest, $X_{i, j}$ is a vector of explanatory variables containing demographic information for both members of the couple, and $Z_{i, j}=$ $\left\{X_{i, j}, D_{i}^{\text {early }}, D_{i}^{\text {normal }}\right\}$.

The vector of explanatory variables $X_{i, j}$ includes a series of controls for the individual and partner $\rrbracket_{s}$ characteristics, such as the respondent $\rrbracket s$ age, the age difference between the two members of the couple, level of education and health status of each member, family composition (whether they have children and grandchildren), country and survey wave dummies.

$D_{i}^{\text {early }}$ is an indicator for eligibility for early retirement pensions, which is defined as:

$D_{i}^{e a r l y}= \begin{cases}1 \text { if individual } i ख \mathrm{~s} \text { age is above the early official retirement age in the country } \\ 0, & \text { otherwise }\end{cases}$ and similarly $D_{i}^{\text {normal }}$ is an indicator for eligibility for full retirement pensions defined as: $D_{i}^{\text {normal }}= \begin{cases}1 \text { if individual } i \bowtie s \text { age is above the full official retirement age in the country } \\ 0, & \text { otherwise }\end{cases}$ $D_{j(i)}^{e a r l y}$ and $D_{j(i)}^{n o r m a l}$ are our external instruments for retirement decisions, that is, they are the exclusion restrictions that allow identification of the model. Note that, identification then relies on partner $₫ s$ age being different than the individual $₫$ s age. As Figure 1 suggests, that is precisely the case in our data. In addition, in our analysis we control for the age difference between the two members of the couple to capture any unobservable characteristics at the couple level revealed by choosing a partner with a certain age difference. $^{7}$

In practice what we assume is that - conditional on observables - whether the partner is eligible for retirement pensions only has an impact on the individual \s retirement decision through the partner囚s retirement decision, as opposed to directly having an effect. Note that our exogeneity assumption does not imply that partner囚s eligibility for retirement pensions does not affect ones $\$ retirement decisions. The assumption is that it does so but only through the actual retirement decision of the partner. Under this assumption, our estimates of $\beta$ are interpreted as the effect of the partner冈s retirement, induced through eligibility for retirement pensions, on the individual邓s retirement decision.

Our econometric approach exploits the fact - illustrated by Figure 3 - that the regressor of interest (transition into retirement) is partly determined by a known discontinuous (non-linear and non-monotonic) function of an observed covariate (age) to control for the endogeneity of partner囚s retirement decisions. This sort of identification strategy has a long tradition in social science and can be viewed as an application of a regression discontinuity design for evaluating the effect of joint retirement. ${ }^{8,9}$

Finally, note that by estimating the equations for both members of the couple jointly we also take into account the potential correlation among unobservables across members of the couple. ${ }^{10}$

\section{Estimation results}

In this section we present the results of jointly estimating the system of equations (1-1). Table 2 reports, separately for men and women, average marginal effects of estimates of probit models for the probability of leaving the labor force, given that both spouses were 


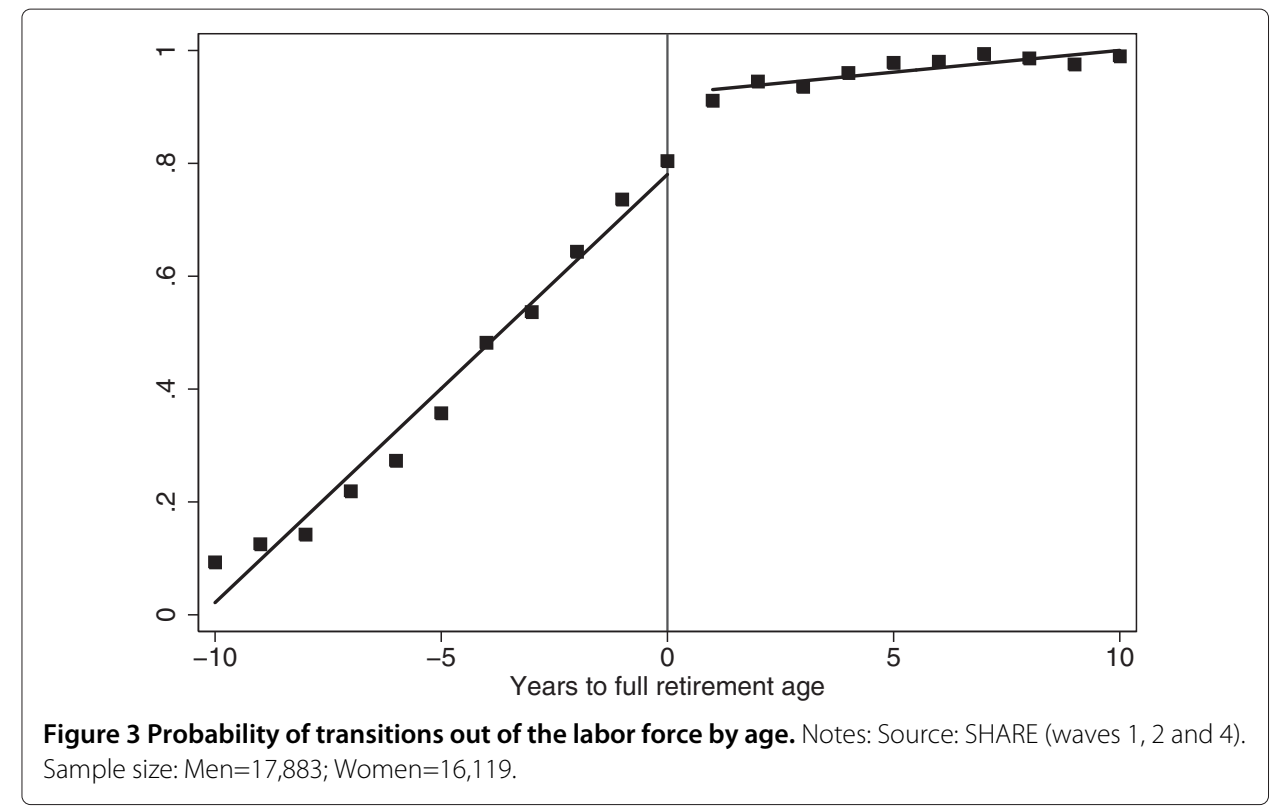

working in the previous wave. The set of controls included in the regressions is the following: dummy variables for the respondent being eligible for early or full retirement, the respondent $\llbracket \mathrm{s}$ age, the age difference between the two members of the couple ${ }^{11}$ country and survey wave dummies, education variables for the two spouses, information on whether the couple has children and grandchildren as a measure of care necessities, and health status controls for both spouses, lagged one period to lessen endogeneity concerns. Within each section of the table we present results of models that ignore the possibility of joint retirement by excluding information on the current working status of the spouse, and preferred bivariate probit models where we include this variable and instrument it with the dummies for spouse凶s eligibility for retirement pensions.

Our results show that there is a significative joint retirement effect for women, of 21 percentage points. For men, the estimated effect is insignificant. These results are similar in size to those found by Banks et al. (2010) for British men. Introducing information on working status of the spouse reduces the impact of own eligibility for retirement pensions for women in about 2 percentage points. Therefore, by ignoring joint retirement, governments would be overstating the impact of eligibility rules on retirement decisions. The remainder of the variables have the expected effects. Higher levels of education lower the probability of leaving the labor force but only for men, whereas bad health has a positive impact on the probability of leaving the labor force only for women. Finally, having grandchildren increases the probability of leaving the labor force for both men and women, while having children reduces the probability of retirement only for men. ${ }^{12}$

In order for the official retirement ages to be valid instruments, they must be exogenous and relevant. With respect to the exogeneity assumption, we assume that if the husband (wife) reaches the statutory retirement age, his (her) spouse邓s retirement decision is only affected through his (her) own transition. This assumption is not testable. Regarding relevance, statutory retirement ages must be related to actual retirement behavior. To illustrate this latter point we estimated probit regressions of the individual probability of leaving the labor force, separately for husbands and wives. This set of regressions 
Table 2 Bivariate probit estimates

\begin{tabular}{|c|c|c|c|c|}
\hline \multirow{2}{*}{$\begin{array}{l}\text { Probability of leaving the labor force } \\
\text { Partner leaving the labor force }\end{array}$} & \multicolumn{2}{|c|}{ Men } & \multicolumn{2}{|c|}{ Women } \\
\hline & & 0.026 & & $0.212^{* * *}$ \\
\hline & & $(0.094)$ & & $(0.063)$ \\
\hline \multirow[t]{2}{*}{ Age> early } & $0.046^{* *}$ & $0.045^{* *}$ & -0.001 & -0.007 \\
\hline & $(0.021)$ & $(0.022)$ & $(0.023)$ & $(0.022)$ \\
\hline \multirow[t]{2}{*}{ Age $>$ full } & $0.165^{* * *}$ & $0.168^{* * *}$ & $0.143^{* * *}$ & $0.125^{* * *}$ \\
\hline & $(0.033)$ & $(0.034)$ & $(0.035)$ & $(0.034)$ \\
\hline \multirow[t]{2}{*}{ Age } & $0.045^{* * *}$ & $0.044^{* * *}$ & $0.047^{* * *}$ & $0.032^{* * *}$ \\
\hline & $(0.003)$ & $(0.006)$ & $(0.003)$ & $(0.006)$ \\
\hline \multirow[t]{2}{*}{ Age difference $<0$} & 0.032 & 0.020 & $-0.039^{*}$ & $0.066^{*}$ \\
\hline & $(0.023)$ & $(0.049)$ & $(0.022)$ & $(0.035)$ \\
\hline \multirow[t]{2}{*}{$0 \leqslant$ Age difference $<1$} & $0.054^{* *}$ & 0.045 & -0.009 & $0.058^{* *}$ \\
\hline & $(0.024)$ & $(0.039)$ & $(0.024)$ & $(0.029)$ \\
\hline \multirow[t]{2}{*}{$1 \leqslant$ Age difference $<2$} & $0.057^{* * *}$ & 0.048 & 0.007 & $0.060^{* *}$ \\
\hline & $(0.022)$ & $(0.036)$ & $(0.023)$ & $(0.026)$ \\
\hline \multirow[t]{2}{*}{$2 \leqslant$ Age difference $<4$} & $0.039^{*}$ & 0.035 & -0.031 & 0.005 \\
\hline & $(0.020)$ & $(0.023)$ & $(0.022)$ & $(0.024)$ \\
\hline \multirow[t]{2}{*}{ High education } & $-0.046^{* *}$ & $-0.047^{* *}$ & -0.029 & -0.018 \\
\hline & $(0.021)$ & $(0.021)$ & $(0.021)$ & $(0.021)$ \\
\hline \multirow[t]{2}{*}{ Medium education } & 0.012 & 0.012 & 0.006 & 0.011 \\
\hline & $(0.018)$ & $(0.018)$ & $(0.018)$ & $(0.017)$ \\
\hline \multirow[t]{2}{*}{ Partner high education } & $-0.045^{* *}$ & $-0.044^{* *}$ & 0.018 & 0.028 \\
\hline & $(0.021)$ & $(0.021)$ & $(0.022)$ & $(0.021)$ \\
\hline \multirow[t]{2}{*}{ Partner medium education } & -0.021 & -0.021 & 0.020 & 0.013 \\
\hline & $(0.018)$ & $(0.018)$ & $(0.018)$ & $(0.017)$ \\
\hline \multirow[t]{2}{*}{ Having children } & $-0.055^{*}$ & $-0.056^{*}$ & 0.030 & 0.033 \\
\hline & $(0.031)$ & $(0.031)$ & $(0.034)$ & $(0.032)$ \\
\hline \multirow[t]{2}{*}{ Having grandchildren } & $0.073^{* * *}$ & $0.072^{* * *}$ & $0.047^{* * *}$ & $0.028^{*}$ \\
\hline & $(0.016)$ & $(0.017)$ & $(0.016)$ & $(0.016)$ \\
\hline \multirow[t]{2}{*}{ Bad health in previous wave } & 0.022 & 0.021 & $0.071^{* * *}$ & $0.071^{* * *}$ \\
\hline & $(0.022)$ & $(0.022)$ & $(0.019)$ & $(0.019)$ \\
\hline \multirow[t]{2}{*}{ Partner bad health in previous wave } & 0.005 & 0.002 & $0.039^{*}$ & 0.031 \\
\hline & $(0.020)$ & $(0.023)$ & $(0.020)$ & $(0.021)$ \\
\hline Log-likelihood & -2524.83 & -2524.21 & -2524.83 & -2513.37 \\
\hline \multirow{2}{*}{$\rho$} & 0.361 & 0.302 & 0.361 & -0.195 \\
\hline & $(0.036)$ & $(0.228)$ & $(0.036)$ & $(0.191)$ \\
\hline \multirow[t]{2}{*}{ LR test of $\rho=0$} & 82.13 & 1.55 & 82.13 & 0.99 \\
\hline & {$[0.00]$} & {$[0.21]$} & {$[0.00]$} & {$[0.32]$} \\
\hline
\end{tabular}

Notes: N. obs $=3,058$. Age difference measured as husband age minus wife age. All specifications include country and survey wave dummies. Delta-method standard errors clustered at the individual level in parentheses. Significant at the ${ }^{*} 10 \%$, ${ }^{*} 5 \%$, and ${ }^{* * *} 1 \%$ level. $\rho=\operatorname{corr}\left(u_{h}, \epsilon_{h}\right)$. p-values in squared brackets.

would represent a standard first-stage step in a two-stage estimation procedure such as an Instrumental Variable (IV) model. ${ }^{13}$ Estimated marginal effects for these regressions can be found in the Appendix (Table 5 in the Appendix). Our results show that eligibility for retirement pensions are a significant predictor of retirement decisions both for husbands and wives. In terms of the model in equations (1-1), these results confirm that $D_{j(i)}^{e a r l y}$ and $D_{j(i)}^{\text {normal }}$ affect $R_{j(i)}$, after controlling for $D_{i}^{\text {early }}$ and $D_{i}^{\text {normal }}$, and the rest of the control variables. ${ }^{14}$ 
To get a better insight of the effect of policies on pension entitlement ages on retirement behaviors of couples, we also estimate bivariate models dividing the sample in two groups of countries. Group 1 includes those countries with a low gap in participation rates by gender, while group 2 contains those countries with high differentials in the participation rates between men and women. The mean gender gap in employment/population ratios for individuals aged 50-64 years in the thirteen countries considered in the analysis is 17.13, as reported in the Appendix (Table 6 in the Appendix). Below that number are the countries with low gender gaps, that is, Belgium, Denmark, France, Germany, Poland, and Sweden; whereas above the mean, we find countries with high gender gaps like Austria, Czechia, Greece, Italy, Netherlands, Spain, or Switzerland. The estimated marginal effects from these regressions are reported in Table 3. As before, the estimated joint retirement effect is insignificant for men, both for groups 1 and 2. On the contrary, for women we find that the significative joint retirement effect is wholly due to those countries where the differences by gender in participation rates are small (that is, group 1, for which the estimated effect is 28 percentage points). On the contrary, for women in countries with large differences in participation rates by gender, the estimated effect of joint retirement is not statistically different from zero.

Finally, to assess the robustness of our results to different definitions of retirement, we also estimated models for the probability that the respondent describes herself as retired as opposed to out of the labor force. The results of these regressions can be found in the Appendix (Table 7 in the Appendix). Our results are still robust to this alternative definition of the dependent variable. For women, we find a significant joint retirement effect, although the magnitude of the effect gets reduced to about half the size (from 21 to 10 percentage points). For men we find an effect similar in magnitude, but again insignificant. Another difference with previous results is that lagged bad health does not seem to have an impact on retirement decisions for women in this case. This suggests that bad health shocks might lead women to rather leave the labor force without actually retiring. More research is needed to better understand the differences between women囚s transitions out of work to self-reported retirement or to homemaking.

\section{Conclusions}

Continued improvements in life expectancy and fiscal insolvency of public pensions have led to an increase in pension entitlement ages in several countries. For example, the normal retirement age in the US is currently rising from 65 to 67 for successive birth cohorts. England, Austria, Germany and Italy are also phasing in increases in their retirement ages. However, the success of such policies relies on how responsive individuals are to such changes in pension eligibility. In this paper we use longitudinal data from SHARE to study the determinants of retirement decisions among European couples and how responsive each member of the couple is to their own eligibility to retirement pensions, as well as their partner囚s eligibility induced retirement choice, after controlling for other factors that may affect their retirement decisions.

Our empirical strategy exploits the discontinuities in retirement behavior across countries to control for the endogeneity of partner囚s labor participation decisions. This allows us to give a causal interpretation to the effects we estimate. Our results show a significative joint retirement effect for women of 21 percentage points. For men, the estimated effect is insignificant. 
Table 3 Bivariate probit estimates

\begin{tabular}{|c|c|c|c|c|}
\hline \multirow{2}{*}{$\begin{array}{l}\text { Probability of leaving the labor force } \\
\text { (By participation rates gap) }\end{array}$} & \multicolumn{2}{|c|}{ Men } & \multicolumn{2}{|c|}{ Women } \\
\hline & Group 1 & Group 2 & Group 1 & Group 2 \\
\hline \multirow[t]{2}{*}{ Partner leaving the labor force } & 0.012 & -0.119 & $0.277^{* * *}$ & 0.107 \\
\hline & $(0.085)$ & $(0.134)$ & $(0.048)$ & $(0.175)$ \\
\hline \multirow[t]{2}{*}{ Age> early } & 0.032 & $0.066^{*}$ & -0.015 & -0.040 \\
\hline & $(0.028)$ & $(0.037)$ & $(0.026)$ & $(0.042)$ \\
\hline \multirow[t]{2}{*}{ Age $>$ full } & $0.150^{* * *}$ & $0.208^{* * *}$ & $0.094^{* *}$ & $0.157^{* *}$ \\
\hline & $(0.046)$ & $(0.054)$ & $(0.038)$ & $(0.065)$ \\
\hline \multirow[t]{2}{*}{ Age } & $0.046^{* * *}$ & $0.043^{* * *}$ & $0.029^{* * *}$ & $0.038^{* * *}$ \\
\hline & $(0.006)$ & $(0.008)$ & $(0.006)$ & $(0.012)$ \\
\hline \multirow[t]{2}{*}{ Age difference $<0$} & 0.025 & 0.089 & $0.073^{* *}$ & 0.051 \\
\hline & $(0.046)$ & $(0.084)$ & $(0.031)$ & $(0.089)$ \\
\hline \multirow[t]{2}{*}{$0 \leqslant$ Age difference $<1$} & $0.078^{* *}$ & 0.053 & 0.011 & $0.143^{*}$ \\
\hline & $(0.035)$ & $(0.088)$ & $(0.029)$ & $(0.077)$ \\
\hline \multirow[t]{2}{*}{$1 \leqslant$ Age difference $<2$} & 0.036 & $0.119^{*}$ & $0.049^{*}$ & 0.086 \\
\hline & $(0.034)$ & $(0.064)$ & $(0.027)$ & $(0.055)$ \\
\hline \multirow[t]{2}{*}{$2 \leqslant$ Age difference $<4$} & 0.041 & 0.047 & -0.003 & 0.019 \\
\hline & $(0.026)$ & $(0.044)$ & $(0.026)$ & $(0.050)$ \\
\hline \multirow[t]{2}{*}{ High education } & $-0.056^{* *}$ & -0.031 & 0.013 & -0.009 \\
\hline & $(0.028)$ & $(0.037)$ & $(0.024)$ & $(0.040)$ \\
\hline \multirow[t]{2}{*}{ Medium education } & 0.017 & -0.014 & $0.066^{* * *}$ & -0.045 \\
\hline & $(0.024)$ & $(0.029)$ & $(0.021)$ & $(0.029)$ \\
\hline \multirow[t]{2}{*}{ Partner high education } & $-0.071^{* * *}$ & 0.018 & $0.075^{* * *}$ & -0.049 \\
\hline & $(0.025)$ & $(0.039)$ & $(0.025)$ & $(0.037)$ \\
\hline \multirow[t]{2}{*}{ Partner medium education } & -0.038 & -0.004 & $0.041^{* *}$ & -0.012 \\
\hline & $(0.025)$ & $(0.029)$ & $(0.021)$ & $(0.030)$ \\
\hline \multirow[t]{2}{*}{ Having children } & -0.024 & -0.047 & -0.015 & 0.072 \\
\hline & $(0.046)$ & $(0.045)$ & $(0.044)$ & $(0.047)$ \\
\hline \multirow[t]{2}{*}{ Having grandchildren } & $0.068^{* * *}$ & $0.093^{* * *}$ & -0.008 & $0.079^{* *}$ \\
\hline & $(0.019)$ & $(0.031)$ & $(0.018)$ & $(0.033)$ \\
\hline \multirow[t]{2}{*}{ Bad health in previous wave } & 0.010 & 0.029 & $0.096^{* * *}$ & 0.024 \\
\hline & $(0.027)$ & $(0.036)$ & $(0.021)$ & $(0.038)$ \\
\hline \multirow[t]{2}{*}{ Partner bad health in previous wave } & -0.037 & $0.086^{* * *}$ & $0.045^{*}$ & 0.005 \\
\hline & $(0.030)$ & $(0.032)$ & $(0.023)$ & $(0.038)$ \\
\hline Log-likelihood & -1632.39 & -847.63 & -1619.35 & -847.11 \\
\hline \multirow[t]{2}{*}{$\rho$} & 0.370 & 0.643 & -0.410 & 0.116 \\
\hline & $(0.195)$ & $(0.279)$ & $(0.173)$ & $(0.443)$ \\
\hline \multirow[t]{2}{*}{ LR test of $\rho=0$} & 2.97 & 2.57 & 4.35 & 0.07 \\
\hline & {$[0.08]$} & {$[0.11]$} & {$[0.04]$} & {$[0.79]$} \\
\hline N. obs & 2,040 & 1,018 & 2,040 & 1,018 \\
\hline
\end{tabular}

We also compare our estimates with models that do not control for the partner】s labor participation decisions and found that introducing information on working status of the spouse reduces the impact of own eligibility for retirement pensions for women in about 2 percentage points. Therefore, by ignoring joint retirement, governments would be overstating the impact of eligibility rules on retirement decisions. 
Finally, our results are still robust to using self-reported retirement status as an alternative definition of the dependent variable. In this case, we find a significant joint retirement effect for women, although the magnitude of the effect gets reduced to about half the size. For men, the estimated effect remains insignificant.

As recent pension reforms that increase pension entitlement ages get established and new waves of data get collected, it would be good to analyze how these reforms are affecting retirement patterns of men and women. Lastly, additional waves of data would allow for the estimation of panel data models that could better control for unobserved heterogeneity affecting transitions out of the labor force.

\section{Endnotes}

${ }^{1}$ Note that Israel is excluded from the group of countries we analyze because it did not join OECD until 2010 and by that time they did not participate in SHARE anymore.

2 In the case of the Netherlands, the modelling at age 60 refers to a $\triangle$ typical $\mathbb{}$ occupational early retirement scheme. However since the early 1990s these schemes have been progressively transformed into less generous, fully-funded, systems. As a result of these transformations, early retirement ages may have a lower incentive effect there than in other countries considered.

3 The distribution of number of couples by country is as follows: 70 couples in Austria, 350 couples in Belgium, 134 couples in Czechia, 454 couples in Denmark, 376 couples in France, 294 couples in Germany, 88 couples in Greece, 128 couples in Italy, 334 couples in the Netherlands, 64 couples in Poland, 98 couples in Spain, 502 couples in Sweden, and 166 couples in Switzerland.

${ }^{4}$ Note that $4 \%$ of women in our couples reported transitioning from work to homemaker. This is in contrast with only $0.4 \%$ of men that reported such transition. Not to lose these transitions from women, we focus on transitions out of the labor force. Transitions to unemployment or disability were lower and did not show gender differences ( $1.7 \%$ of men reported transitioning to disability vs. $1.3 \%$ of women; $2.3 \%$ of men reported transitioning to unemployment vs. $2.2 \%$ of women). In any case, in the empirical analysis we also study only transitions to self-reported retirement status as the dependent variable and results are robust to this alternative definition.

${ }^{5}$ It should be pointed out that our approach, focusing on transitions out of the labor force for working couples on waves 1 or 2 , is equivalent to a discrete duration model for durations in the labor force where we assume that coefficients are constant across durations.

${ }^{6}$ In our sample, 550 out of the 3,058 couples are observed working both in waves 1 and 2 and so they contribute twice to our sample. To take this into account we obtain cluster robust standard errors at the respondent level. Note that the limited number of couples that appear in both waves and the limited number of waves do not allow us to estimate more sophisticated panel models to control for unobserved heterogeneity.

7 For instance, those who have partners who are much younger than themselves might have a certain personality that could reflect in their retirement decisions. This could be confounded with the effect of having a spouse that does not retire if not controlled for.

8 For literature reviews of regression discontinuity methods see Imbens and Lemieux 2007, Van der Klaauw 2008, or Lee and Lemieux 2010. For applications of regression discontinuity to the retirement decision see also Battistin et al. 2009, and Stancanelli and van Soest 2012a, 2012b.

9 It should be pointed out that, if the effect of partnerखs retiring on own retirement choices is heterogeneous among individuals, our results would then be interpreted as the average effect of those whose partners change their retirement decisions when they become eligible for retirement pensions. As eligibility for retirement pensions, especially for early retirement, depends on many cases of the labor history of the individual, our 
estimates would be more representative of effects for those whose partners have longer labor histories which might not necessarily coincide with those for the whole population.

10 An alternative model would consist on an Instrumental Variables (IV) discrete choice model estimated separately for men and women. However, this approach would be less efficient than the simultaneous discrete choice model models we estimate and it would not account for the potential correlation among unobservables across spouses.

11 The age of the respondent is included as a continuous variable (measuring age in months), whereas the age gap between spouses enters as dummies.

12 We also estimated models controlling for household income in the previous wave and household wealth but this did not change our main results. Estimates for these models are available from the authors upon request.

13 In practice, we follow a more efficient approach and estimate the whole bivariate model by maximum likelihood in a single step.

14 The estimated model in this paper is a simultaneous equation binary choice model where partner囚s eligibility for early and full retirement pensions is used as exclusion restrictions to identify the system. As such, the reduced form probit models that we estimate just proxy what it would be a first step to assess the relevance of our instruments. Moreover, in order to also approximate traditional Hausman/Sargan test for the joint validity of the instruments, we have tried and estimate reduced form linear models for the probability of individual $i$ leaving the labor force, separately for men and women, by Two-Stage Least Squares. In these models, the partner囚s transition out of the labor force, $R_{i(i)}$, is instrumented using the indicators $D_{j(i)}^{e a r l y}$ and $D_{j(i)}^{n o r m a l}$. For these latter regressions, we obtained the Sargan test of overidentifying restrictions. For men the corresponding $\mathrm{p}$-value for the test was 0.274 , whereas for women was 0.869 ; meaning that in both cases we can not reject the null hypothesis that the over-identifying restrictions are valid.

\section{Appendix}

Given the aim of the analysis, we focus on working couples only. Table 4 reports descriptive statistics by gender for our sample of working couples.

However, for some countries, this sample would not be representative of the whole middle-age and older population. On the one hand, as shown in Figure 4, some European countries have very high proportions of women who never worked. In

Table 4 Descriptive statistics by gender

\begin{tabular}{|c|c|c|c|}
\hline & [1] Men & [2] Women & Dif $=[1]-[2]$ \\
\hline \multirow[t]{2}{*}{ Age } & 60.040 & 58.376 & $1.664^{* * *}$ \\
\hline & $(3.792)$ & $(3.618)$ & \\
\hline Over Early Age & 0.329 & 0.215 & $0.114^{* * *}$ \\
\hline Over Normal Age & 0.109 & 0.065 & $0.044^{* * *}$ \\
\hline Out of the labor force & 0.294 & 0.253 & $0.041^{* * *}$ \\
\hline Declared as retired & 0.250 & 0.173 & $0.077^{* * *}$ \\
\hline Bad Health & 0.151 & 0.169 & $-0.018^{* *}$ \\
\hline Low Education & 0.248 & 0.263 & $-0.015^{*}$ \\
\hline Medium Education & 0.389 & 0.366 & $0.023^{* *}$ \\
\hline High Education & 0.355 & 0.361 & $-0.006^{*}$ \\
\hline Dummy of having children & \multicolumn{2}{|c|}{0.942} & \\
\hline Dummy of having grandchildren & \multicolumn{2}{|c|}{0.587} & \\
\hline
\end{tabular}

Notes: 3,058 observations for men and 3,058 observations for women. Standard deviations of non-binary variables in parentheses. Significant at the $* 10 \%, * * 5 \%$, and ${ }^{* *} 1 \%$ level. 


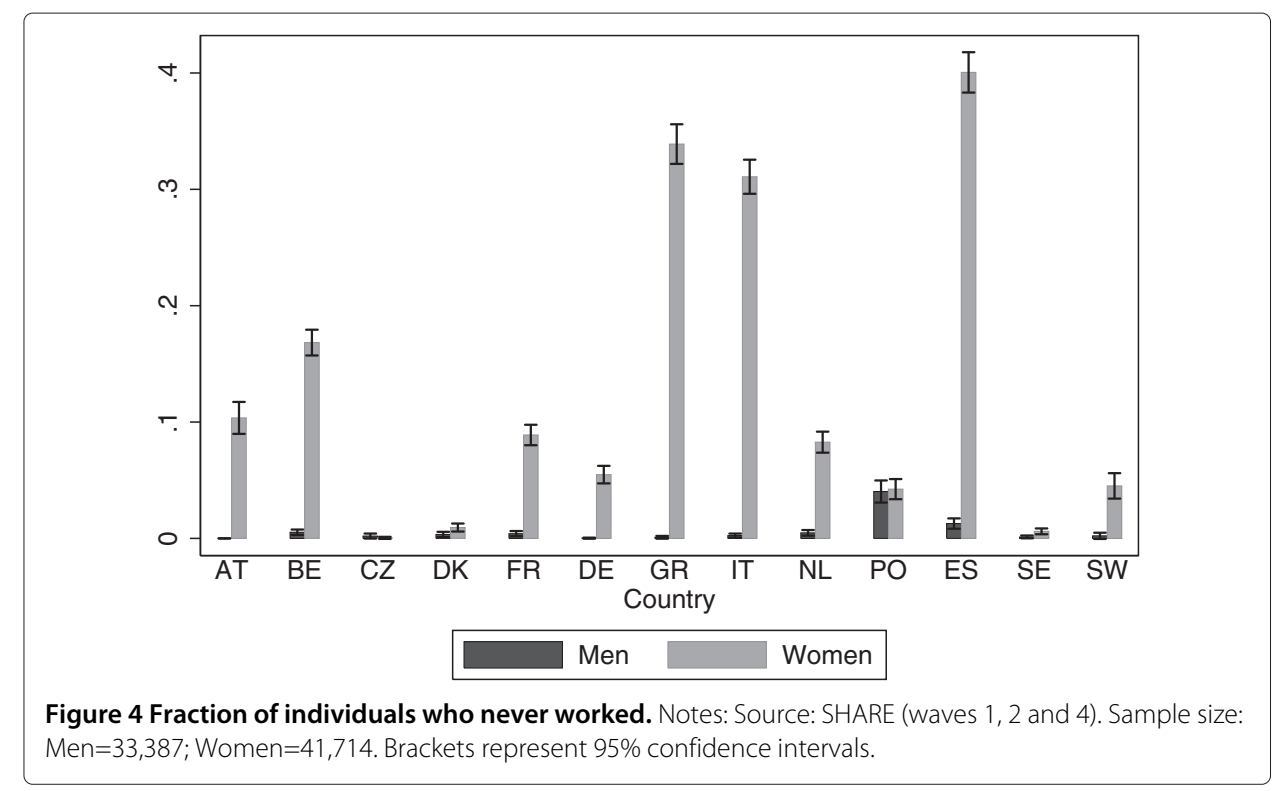

addition, a large proportion of women who ever worked but stopped before age 50 did so at the early stages of their careers. For instance, in Figure 5 we can see bimodal histogram shapes for women in countries like Belgium, Italy, the Netherlands or Spain.

Table 5 reports estimated marginal effects from probit regressions of the individual probability of leaving the labor force, separately for husbands and wives. This set

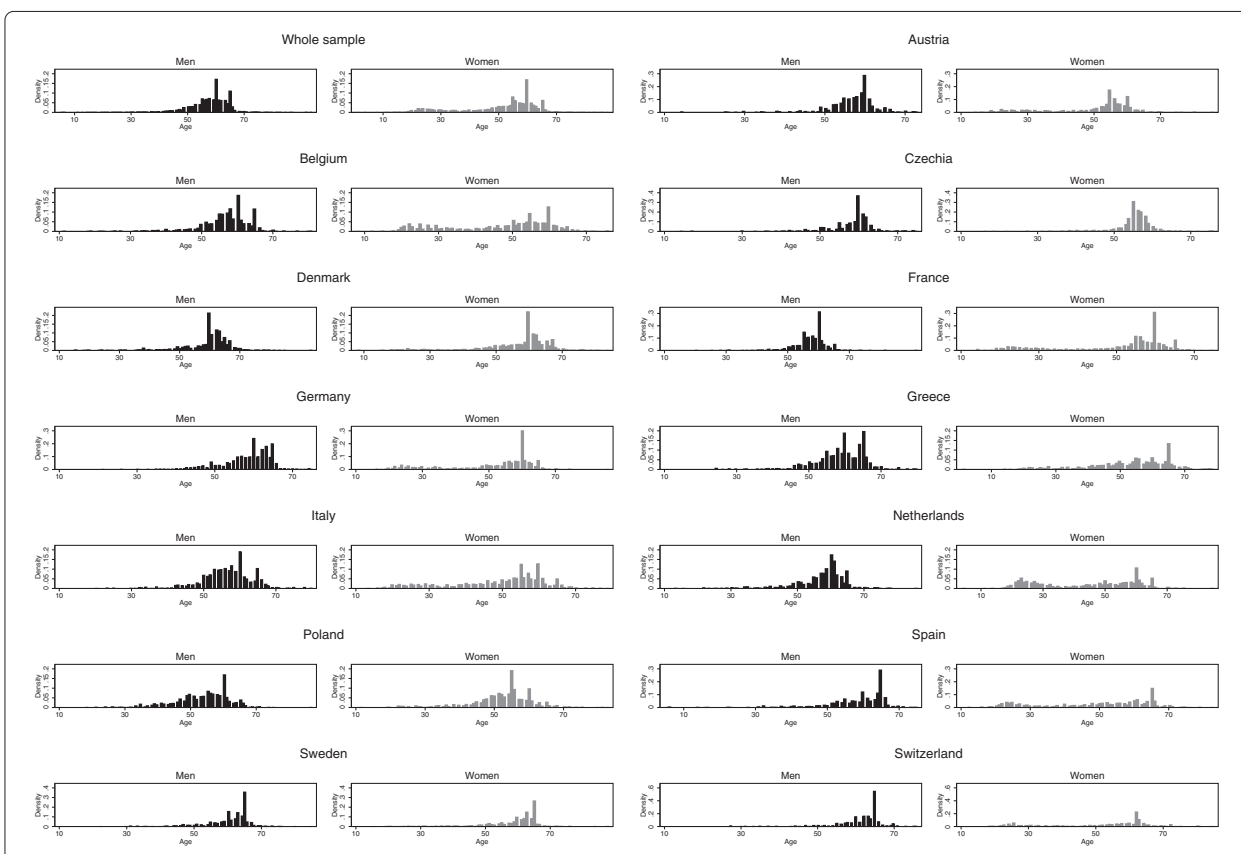

Figure 5 Stop working age. Notes: Source: SHARE (waves 1, 2 and 4). Sample size: Men=32,926; Women $=34,260$. 
Table 5 Probit estimates

\begin{tabular}{|c|c|c|}
\hline Probability of leaving the labor force & Men & Women \\
\hline \multirow[t]{2}{*}{ Age > early } & $0.056^{*}$ & -0.002 \\
\hline & $(0.030)$ & $(0.028)$ \\
\hline \multirow[t]{2}{*}{ Age $>$ full } & $0.284^{* * *}$ & $0.162^{* * *}$ \\
\hline & $(0.058)$ & $(0.060)$ \\
\hline \multirow[t]{2}{*}{ Partner age> early } & 0.008 & -0.001 \\
\hline & $(0.029)$ & $(0.026)$ \\
\hline \multirow[t]{2}{*}{ Partner age $>$ full } & $-0.104^{* *}$ & 0.036 \\
\hline & $(0.034)$ & $(0.042)$ \\
\hline \multirow[t]{2}{*}{ Age } & $0.059^{* * *}$ & $0.055^{* * *}$ \\
\hline & $(0.005)$ & $(0.004)$ \\
\hline \multirow[t]{2}{*}{ Age difference $<0$} & $0.079^{* *}$ & -0.033 \\
\hline & $(0.037)$ & $(0.032)$ \\
\hline \multirow[t]{2}{*}{$0 \leqslant$ Age difference $<1$} & $0.097^{* * *}$ & -0.002 \\
\hline & $(0.037)$ & $(0.033)$ \\
\hline \multirow[t]{2}{*}{$1 \leqslant$ Age difference $<2$} & $0.096^{* * *}$ & 0.022 \\
\hline & $(0.033)$ & $(0.032)$ \\
\hline \multirow[t]{2}{*}{$2 \leqslant$ Age difference $<4$} & $0.062^{* *}$ & -0.029 \\
\hline & $(0.028)$ & $(0.026)$ \\
\hline \multirow[t]{2}{*}{ High education } & $-0.062^{* *}$ & -0.032 \\
\hline & $(0.025)$ & $(0.024)$ \\
\hline \multirow[t]{2}{*}{ Medium education } & 0.010 & 0.010 \\
\hline & $(0.022)$ & $(0.022)$ \\
\hline \multirow[t]{2}{*}{ Partner high education } & $-0.052^{* *}$ & 0.022 \\
\hline & $(0.025)$ & $(0.027)$ \\
\hline \multirow[t]{2}{*}{ Partner medium education } & -0.028 & 0.021 \\
\hline & $(0.022)$ & $(0.022)$ \\
\hline \multirow[t]{2}{*}{ Having children } & $-0.072^{*}$ & 0.029 \\
\hline & $(0.044)$ & $(0.037)$ \\
\hline \multirow[t]{2}{*}{ Having grandchild } & $0.086^{* * *}$ & $0.054^{* * *}$ \\
\hline & $(0.019)$ & $(0.018)$ \\
\hline \multirow[t]{2}{*}{ Bad health previous wave } & 0.024 & $0.091^{* * *}$ \\
\hline & $(0.028)$ & $(0.027)$ \\
\hline \multirow[t]{2}{*}{ Partner bad health previous wave } & 0.008 & $0.050^{*}$ \\
\hline & $(0.025)$ & $(0.027)$ \\
\hline Pseudo $R^{2}$ & 0.303 & 0.267 \\
\hline
\end{tabular}

Notes: $\mathrm{N}$. obs $=3,058$. Age difference measured as husband age minus wife age. All specifications include country and wave dummies. Standard errors clustered at the individual level in parentheses. Significant at ${ }^{*} 10 \%,{ }^{* *} 5 \%,{ }^{* * *} 1 \%$.

of regressions would represent a standard first-stage step in a two-stage estimation procedure such as an Instrumental Variable (IV) model. Results show that eligibility for retirement pensions are a significant predictor of retirement decisions both for men and women.

Table 6 shows gender gaps in employment/population ratios, by country, for individuals aged 50-64 years.

Finally, Table 7 shows estimation results of models for the probability that the respondent describes herself as retired as opposed to out of the labor force. Our results are robust to this alternative definition of the dependent variable. 
Table 6 Employment/population ratios (50-64 years)

\begin{tabular}{lcccc}
\hline Country & Total & [1] Men & [2] Women & Dif=[1]-[2] \\
\hline Austria & 39.22 & 50.57 & 28.23 & 22.34 \\
Belgium & 45.26 & 52.74 & 37.88 & 14.86 \\
Czechia & 50.01 & 62.17 & 39.60 & 22.57 \\
Denmark & 67.52 & 72.81 & 62.48 & 10.33 \\
France & 53.58 & 57.22 & 50.26 & 6.96 \\
Germany & 56.99 & 62.80 & 51.34 & 11.46 \\
Greece & 51.04 & 73.47 & 30.24 & 43.23 \\
Italy & 38.22 & 51.48 & 26.14 & 25.34 \\
Netherlands & 55.94 & 65.50 & 46.23 & 19.27 \\
Poland & 31.79 & 40.57 & 23.98 & 16.59 \\
Spain & 46.79 & 63.53 & 31.10 & 32.43 \\
Sweden & 76.35 & 79.26 & 73.45 & 5.81 \\
Switzerland & 71.18 & 80.75 & 61.71 & 19.04 \\
Overall & 50.65 & 59.48 & 42.35 & 17.13 \\
\hline
\end{tabular}

Notes: Source: SHARE (waves 1, 2, and 4). Sample size: Men=16,261; Women=20,176. Weighted means.

Table 7 Bivariate probit estimates

\begin{tabular}{|c|c|c|}
\hline Probability of retiring & Men & Women \\
\hline \multirow{2}{*}{ Partner leaving the labor force } & 0.104 & $0.097^{* *}$ \\
\hline & $(0.064)$ & $(0.041)$ \\
\hline \multirow[t]{2}{*}{ Age> early } & $0.043^{* *}$ & -0.001 \\
\hline & $(0.018)$ & $(0.018)$ \\
\hline \multirow[t]{2}{*}{ Age $>$ full } & $0.096^{* * *}$ & $0.058^{* *}$ \\
\hline & $(0.028)$ & $(0.026)$ \\
\hline \multirow[t]{2}{*}{ Age } & $0.043^{* * *}$ & $0.037^{* * *}$ \\
\hline & $(0.005)$ & $(0.004)$ \\
\hline \multirow[t]{2}{*}{ Age difference $<0$} & -0.052 & 0.051 \\
\hline & $(0.037)$ & $(0.031)$ \\
\hline \multirow[t]{2}{*}{$0 \leqslant$ Age difference $<1$} & -0.005 & $0.047^{*}$ \\
\hline & $(0.030)$ & $(0.025)$ \\
\hline \multirow[t]{2}{*}{$1 \leqslant$ Age difference $<2$} & 0.016 & $0.051^{* *}$ \\
\hline & $(0.026)$ & $(0.022)$ \\
\hline \multirow[t]{2}{*}{$2 \leqslant$ Age difference $<4$} & 0.004 & 0.014 \\
\hline & $(0.019)$ & $(0.021)$ \\
\hline \multirow[t]{2}{*}{ High education } & -0.029 & 0.026 \\
\hline & $(0.020)$ & $(0.016)$ \\
\hline \multirow[t]{2}{*}{ Medium education } & 0.024 & -0.003 \\
\hline & $(0.016)$ & $(0.014)$ \\
\hline \multirow[t]{2}{*}{ Partner high education } & -0.028 & 0.002 \\
\hline & $(0.020)$ & $(0.017)$ \\
\hline \multirow[t]{2}{*}{ Partner medium education } & -0.023 & 0.014 \\
\hline & $(0.016)$ & $(0.014)$ \\
\hline \multirow[t]{2}{*}{ Having children } & -0.047 & 0.037 \\
\hline & $(0.029)$ & $(0.028)$ \\
\hline \multirow[t]{2}{*}{ Having grandchildren } & $0.081^{* * *}$ & $0.024^{*}$ \\
\hline & $(0.015)$ & $(0.013)$ \\
\hline \multirow[t]{2}{*}{ Bad health in previous wave } & -0.030 & 0.017 \\
\hline & $(0.019)$ & $(0.015)$ \\
\hline \multirow[t]{2}{*}{ Partner bad health in previous wave } & -0.010 & 0.015 \\
\hline & $(0.017)$ & $(0.017)$ \\
\hline
\end{tabular}


Table 7 Bivariate probit estimates (Continued)

\begin{tabular}{lcc}
\hline Log-likelihood & -1845.45 & -1838.39 \\
$\rho$ & 0.179 & 0.121 \\
& $(0.207)$ & $(0.174)$ \\
LR test of $\rho=0$ & 0.72 & 0.47 \\
& {$[0.40]$} & {$[0.49]$} \\
\hline
\end{tabular}

Notes: N. obs=3,058. Age difference measured as husband age minus wife age. All specifications include country and survey wave dummies. Delta-method standard errors clustered at the individual level in parentheses. Significant at ${ }^{*} 10 \%,{ }^{* *} 5 \%$, and ${ }^{* * *} 1 \% . \rho=\operatorname{corr}\left(u_{h}, \epsilon_{h}\right)$. p-values in squared brackets.

\section{Competing interests}

The IZA Journal of European Labor Studies is committed to the IZA Guiding Principles of Research Integrity. The authors declare that they have observed these principles.

\section{Acknowledgements}

We thank Jorge Alonso, Marco Angrisani, Manuel Bagues, Olympia Bover, Pedro Mira, two anonymous referees, and the seminar participants at the Bank of Spain, the COSME Workshop in Madrid, the 2nd International SHARE User Conference in Mainz, the SAEe in Madrid and in Santander, the ESPE Meeting in Hangzhou, the Netspar International Pension Workshop in Amsterdam, and the ESEM meetings in Malaga for useful comments. All remaining errors are our own. This paper uses data from SHARE wave 4 release 1.1.1, as of March 28th 2013 or SHARE wave 1 and 2 release 2.6.0, as of November 29th 2013 or SHARELIFE release 1, as of November 24th 2010. The SHARE data collection has been primarily funded by the European Commission through the 5th Framework Programme (project QLK6-CT-2001-00360 in the thematic programme Quality of Life), through the 6th Framework Programme (projects SHARE-13, RII-CT-2006-062193, COMPARE, CIT5- CT-2005-028857, and SHARELIFE, CIT4-CT-2006-028812) and through the 7th Framework Programme (SHARE-PREP, N ํ 211909, SHARE-LEAP, N²27822 and SHARE M4, № 261982). Additional funding from the U.S. National Institute on Aging (U01 AG09740-13S2, P01 AG005842, P01 AG08291, P30 AG12815, R21 AG025169, Y1-AG-4553-01, IAG BSR06-11 and OGHA 04-064) and the German Ministry of Education and Research as well as from various national sources is gratefully acknowledged (see www.share-project.org for a full list of funding institutions). The opinions and analyses are the responsibility of the authors and, therefore, do not necessarily coincide with those of the Bank of Spain or the Eurosystem.

Responsible editor: Martin Kahanec

\section{Author details}

${ }^{1}$ Bank of Spain and IZA, Madrid, Spain. ${ }^{2}$ Dornsife Center for Economic and Social Research University of Southern California, Los Angeles, CA, USA.

Received: 17 July 2013 Accepted: 18 January 2014

Published: 20 Jun 2014

\section{References}

Banks J, Blundell R, Casanova M (2010) The dynamics of retirement behavior in couples: reduced-form evidence from England and the US. http://www.econ.ucla.edu/casanova/Files/Main_ELSA_HRS.pdf

Battistin E, Brugiavini A, Rettore E, Weber G (2009) The retirement consumption puzzle: evidence from a regression discontinuity approach. Am Econ Rev 99(5):2209?2226

Blau D, Gilleskie D (2006) Health insurance and retirement of married couples. J Appl Econ 21(7):935?953

Casanova M (2010) Happy together: a structural model of couples? joint retirement choices. http://www.econ.ucla.edu/ casanova/Files/Casanova_joint_ret.pdf

Coe N, Zamarro G (2011) Retirement effects on health in Europe. J Health Econ, Elsevier 30(1):77?86

Coile C (2004a) Retirement incentives and couple?s retirement decisions. Top Econ Anal Policy 4(1):article 17

Coile C (2004b) Health shocks and couple?s labor supply decisions. NBER Working Paper 10810. http://www.nber.org/ papers/w10810

Gustman A, Steinmeier T (2000) Retirement in dual-career families: a structural model. J Lab Econ 18(3):503?545

Gustman A, Steinmeier T (2004) Social security, pensions and retirement behaviour with the family. J Appl Econometrics 19:723-737

Gustman A, Steinmeier T (2009) Integrating retirement models. NBER Working Paper 15607. http://www.nber.org/ papers/W15607

Gruber J, Wise D $(1999,2004)$ Social security programs and retirement around the world. University of Chicago Press, Chicago

Honoré B, de Paula A (2013) Interdependent durations in joint retirement, cemmap working paper CWP05/13. http:// www.cemmap.ac.uk/cemmap/publication/id/6632

Hurd MD (1990) Research on the elderly: economic status, retirement, and consumption and savings. J Econ Lit 28:565-637

Imbens G, Lemieux T (2007) Regression discontinuity design: a guide to practice. J Econometrics 142:615?635

Lee DS, Lemieux T (2010) Regression discontinuity designs in economics. J Econ Lit 48(2):281?355

Lumsdaine RL, Mitchell OS (1999) New Developments in the Economic Analysis of Retirement. In: Ashenfelter O, Card D (eds) Handbook of Labor Economics, 3C, Amsterdam, North Holland, pp 3261?3307 
Michaud P (2003) Joint labor supply dynamics of older couples, IZA DP 832. http://ftp.iza.org/dp832.pdf Michaud P, Vermeulen F (2004) A collective retirement model: identification and estimation in the presence of externalities, IZA DP 1294. http://ftp.iza.org/dp1294.pdf

Natali D (2004) The Pension System Observatoire Social Européen. Research Project. La Methode Ouverte de Coordination (MOC) en matiere des pensions et de l?integration Europeenne. Service Public Fédéral Sécurité Sociale. OECD (2003) Economic Survey of Austria. chapter 3: Pensions. http://www.oecd.org/dataoecd/5/16/27424371.pdf

OECD (2005a) Vieillissement et politiques de I?emploi. France, Ageing and Employment Policies. http://www.oecd.org/ dataoecd/52/58/34591763.pdf

OECD (2005b) OECD Pensions at a Glance 2005: public policies across OECD countries. OECD Publishing. http://www. oecd-ilibrary.org/finance-and-investment/oecd-pensions-at-a-glance-2005_pension_glance-2005-en

OECD (2007) Pensions at a Glance 2007: public policies across OECD countries. OECD Publishing. http://www.oecdilibrary.org/finance-and-investment/oecd-pensions-at-a-glance-2007_pension_glance-2007-en

OECD (2009) Pensions at a Glance 2009: retirement-income systems in OECD countries. OECD Publishing. http://www. oecd-ilibrary.org/finance-and-investment/pensions-at-a-glance-2009_pension_glance-2009-en

OECD (2011) Pensions at a Glance 2011: retirement-income systems in OECD and G20 countries. OECD Publishing. http://www.oecd-ilibrary.org/finance-and-investment/pensions-at-a-glance-2011_pension_glance-2011-en

Preesman L (2006) Dutch to abolish civil service retirement age. IPE International Publishers Ltd., Netherlands

Ruhm CJ (1996) Do pensions increase the labor supply of older men?. J Pub Econ 59(2):157?175

Stancanelli E (2012) Spouses? retirement and hours outcomes: evidence from twofold regression discontinuity with differences-in-differences, IZA DP No. 6791. http://ftp.iza.org/dp6791.pdf

Stancanelli E, van Soest A (2012a) Retirement and home production: a regression discontinuity approach. Am Econ Rev 102(3):600-605

Stancanelli E, van Soest A (2012b) Joint leisure before and after retirement: a double regression discontinuity approach. IZA DP 6698. http://ftp.iza.org/dp6698.pdf

Sundén A (2004) The future of retirement in Sweden. PRC WP 2004-16. Pension Research Council Working Paper, Pension Research Council. http://citeseerx.ist.psu.edu/viewdoc/download?doi=10.1.1.201.9427\&rep=rep1\&type=pdf

The Bertelsmann Foundation, International Reform Monitor (2010) Country info. http://www.bertelsmann-stiftung.de/ cps/rde/xchg/SID-465C2575-83F7BF1C/bst_engl/hs.xsl/54224_104034.htm

Van der Klaauw, W (2008) Regression-discontinuity analysis: a survey of recent developments in economics. Labour 22(2):219?245. http://onlinelibrary.wiley.com/doi/10.1111/j.1467-9914.2008.00419.x/abstract

10.1186/2193-9012-3-12

Cite this article as: Hospido and Zamarro: Retirement patterns of couples in Europe. IZA Journal of European Labor Studies 2014, 3:12

\section{Submit your manuscript to a SpringerOpen ${ }^{\odot}$ journal and benefit from:}

$\checkmark$ Convenient online submission

- Rigorous peer review

- Immediate publication on acceptance

- Open access: articles freely available online

- High visibility within the field

- Retaining the copyright to your article

Submit your next manuscript at $\boldsymbol{\wedge}$ springeropen.com 